\title{
Short Communication: Two-Phase Coriolis Mass Flow Metering with High Viscosity Oil
}

Michael Tombs, Feibiao Zhou, Manus Henry, University of Oxford.

\author{
Corresponding Author: $\quad$ Manus Henry \\ Department of Engineering Science \\ Parks Road, Oxford OX1 3PJ. \\ Tel +44 1865273913 \\ Fax +441865273021 \\ manus.henry@eng.ox.ac.uk
}

\begin{abstract}
Previous work has described the use of Coriolis mass flow metering for multiphase flows, with applications in the oil and gas industry. This paper describes the development and testing of a Coriolis two-phase flow metering solution for nitrogen/synthetic oil mixtures with viscosities ranging from $50 \mathrm{cSt}$ to $500 \mathrm{cSt}$, and with Gas Volume Fractions (GVFs) ranging from $0 \%$ to 90\%. Formal trials took place at the UK National Flow Laboratory. A single synthetic oil was used; its viscosity was adjusted by controlling temperature. The results show that Coriolis metering is well suited to high viscosity oil/gas mixtures: in the formalized trials, mass flow errors for gas were mostly within $5 \%$ and for liquid were mostly within $2.5 \%$. Achieving this accuracy up to $90 \%$ GVF represents an advance on previous work, which has been limited to around $50 \%$ GVF for low viscosity oils in two-phase and three-phase mixtures.
\end{abstract}

Keywords: Coriolis; Mass Flow; Neural Net; Multi Phase Flow; Two Phase Flow; Oil and Gas; high viscosity oil. 


\section{Overview and Results}

Coriolis mass flow metering [1] is a widely used measurement technique. Originally it was applied only to pure liquid or gas flows, but in recent years its use has been extended to mixtures of gas and liquid. The first requirement for multiphase flow metering is a transmitter capable of maintaining flowtube oscillation through the high and rapidly changing mechanical damping induced by gas/liquid mixtures. Thereafter, correction strategies are required for the large but often repeatable mass flow and density errors induced by multiphase flow; for example, correction may be implemented using neural nets [2].

The results reported here are based on a three-phase (oil/water/gas) metering system which combines a Coriolis meter with a water cut meter, and pressure and temperature sensors, described in [3]. This metering system has been certified via GOST R 8.615 [4] for upstream oil and gas operation in Russia; recent field experience is described in [5]. The results in [3] cover the full range of water cut $(0 \% \ldots 100 \%)$, but only includes gas void fraction (GVF) up to $50 \%$. At higher GVFs repeatability is poor, attributable in part to a relatively slow measurement update rate $(1 \mathrm{~Hz})$ compared with the rapid slugging observed in the experimental facility for these conditions [3].

Globally, an increasing proportion of remaining oil reserves contain 'heavy' oil (i.e. having high density and viscosity), and there is significant interest in developing metering techniques for multiphase flows suited to these conditions, particularly as conventional separators for well testing may operate poorly with tightly bound emulsions of viscous oil and water.

Other authors have examined the influence of high viscosity liquids on Coriolis meters, including the case of gas/liquid mixtures, from both theoretical $[6,7]$ and experimental [8] perspectives. In [7], the authors develop models to account for phase decoupling and (gas bubble) compressibility effects. While the mass flow and density error functions predicted bear a 
broad similarity to the empirical results reported here and elsewhere, the models are unable to account for flowtube geometry other than straight pipework (known to have a significant influence [9]), and inhomogeneous flows, which is a particular feature of the low velocity fluids considered here. In [8], the authors carry out an experimental investigation into the influence of high liquid viscosity and air/oil mixtures on the mass flow and density errors of two commercial Coriolis meters, working with the same NEL flow loop used is the current work. Unfortunately, there is limited scope for direct comparison with the results reported here. The GVF used in [8] does not exceed 10\%: presumably this is a limitation of the flowtube drive mechanism of the commercial meters, whereas the digital flowtube drive [10] used in the current work prevents flowtube stalling for most multiphase mixtures, including GVFs up to $90 \%$. The relatively small errors induced in Coriolis mass flow measurements for high viscosity and hence low Reynolds numbers flows described in [8] are not readily explored in the experimental procedures used here, where there are relatively rapid changes between 'zero' GVF and high GVF conditions. Our long-term experience shows that once gas has been introduced into a viscous fluid, it may take hours for the gas to be completely expunged, so that nominally zero GVF fluids may retain small quantities of gas. While this is not a significant problem when measuring the large mass flow and density errors induced by two-phase flow, residual gas in a nominally pure liquid may introduce relatively significant distortions in the data when attempting to track the small errors induced by viscosity effects only.

In this paper we report on the development and validation of models for two-phase (gas/oil) flow using nitrogen and a synthetic oil with high viscosity. Both the model development and formal trials took place at NEL, the UK National Flow Laboratory, located near Glasgow. This work contrasts with a previously reported trial [9] on two phase high viscosity gas/oil mixtures, in the following respects: 
- In [9], a standalone Coriolis mass flow meter with a 75mm diameter flowtube was under test, working with modified transmitter software; here the Net Oil and Gas (NOG) skid [3] is used, with its distinctive flow path geometry and computational architecture, and incorporating a 50mm flowtube. As only a two phase oil/gas mixture is under consideration here, the water cut meter output is not included in any of the calculations or analysis.

- In [9], the viscosity is essentially kept constant, at around $200 \mathrm{cSt}$, whereas in this work the viscosity is varied from $50 \mathrm{cSt}-500 \mathrm{cSt}$, by varying the temperature of the test oil between $15^{\circ} \mathrm{C}$ and $60{ }^{\circ} \mathrm{C}$. Note that [9] shows the desirability of correcting for changing viscosity, as it demonstrates the reduced accuracy of a model based only on $200 \mathrm{cSt}$ data when the viscosity is raised to $300 \mathrm{cSt}$ ([9], compare Figs 9 and 11).

- The mass flow and density error modelling in [9] is based on two parameters, whereby each error is predicted based upon the apparent mass flow and density measurement. Here, a three parameter modelling technique similar to that used in [3] is applied. Essentially, fluid viscosity replaces water cut (in [3]) as the third input used to predict the mass flow and density errors. The fluid viscosity is calculated based on a simple low dimensional polynomial of observed temperature, where the polynomial coefficients are configurable parameters supplied by the user. This approach enables successful modelling over a 10:1 variation in viscosity.

The experimental procedure was similar to that described in [3]. The flow rates of single phase oil and nitrogen gas were metered prior to mixing; the test skid was positioned $6 \mathrm{~m}$ downstream of the gas injection stage. For each experimental point, the gas and oil mass flow errors were determined by comparing the reference single phase measurements with those reported by the meter under test. The reference liquid measurement had an uncertainty of $0.1 \%$ of reading while the reference gas measurement had an uncertainty of $0.5 \%$ of reading: these uncertainties were acceptably small for determining the test meter error in multiphase flow 
conditions. Viscosity was adjusted by varying the temperature of the oil. For each experimental point, the desired temperature (and hence viscosity), liquid and gas mass flows were established and kept constant during data collection. The three dimensional model was developed using 1159 test points, each of $120 \mathrm{~s}$ duration. The formal test points, selected to match the criteria stipulated in the GOST standard [4], were of 300s duration. For example, Fig. 1 shows the uncorrected density and mass flow errors for oil viscosity of approximately $500 \mathrm{cSt}$ and for GVFs up to $90 \%$.

After data collection and modelling, additional formalized trials were carried out at NEL using a test grid designed to match the recommended practice for GOST testing, as follows. The nominal maximum flow rate of the $50 \mathrm{~mm}$ flowtube corresponds to a pressure drop of $100 \mathrm{kPa}$; for water this is approximately $11 \mathrm{~kg} / \mathrm{s}$ while for high viscosity $(500 \mathrm{cSt})$ oil it is approximately $4.0 \mathrm{~kg} / \mathrm{s}$. Accordingly, flow rates of $3.8 \mathrm{~kg} / \mathrm{s}, 3.2 \mathrm{~kg} / \mathrm{s}, 2.0 \mathrm{~kg} / \mathrm{s}$ and $0.8 \mathrm{~kg} / \mathrm{s}$ were selected, corresponding to $95 \%, 80 \%, 50 \%$ and $20 \%$ of the nominal flow rate. These flow points were augmented by further trials at $6 \mathrm{~kg} / \mathrm{s}$ (with reduced viscosity) and $0.6 \mathrm{~kg} / \mathrm{s}$ (for the highest GVFs values).

GVF test values ranged from $0 \%$ to $90 \%$ in $10 \%$ steps. As two-phase mixtures generate higher pressure drops than the corresponding liquid-only flow rate, the test point parameters of viscosity, flow rate and GVF were selected so as not to generate a pressure drop in excess of 150 $\mathrm{kPa}$ across the flowtube. Hence, typically higher GVFs were tested at lower flow rates and/or lower viscosities. Table 1 summarizes the 17 sets of parameters values, while Figure 2 shows GVF (upper plot) and viscosity (lower plot) against flow rate. The recording period for each test point was 5 minutes, other than the point at $0.6 \mathrm{~kg} / \mathrm{s}$ and $90 \% \mathrm{GVF}$ where the recording period was 10 minutes. For most test points, three repeat trials were carried out; in two cases an additional trial was carried out, thus yielding a total of 53 experimental results. 
Figures 3 and 4 show the results from the formally witnessed trials at NEL for the liquid and gas mass flow rate errors, where in each case the same results are plotted against true liquid flow rate (upper), GVF (middle) and fluid viscosity (lower).

In Figure 3, 49 out of 53 liquid mass flow errors fall within the $\pm 2.5 \%$ error limit recommended by the GOST R 8.615 standard. The largest error by magnitude is approximately $-3.3 \%$. The majority of errors exceeding the GOST limit occur at low liquid flow rates, where achieving a small percentage error is more difficult. At the highest viscosity, approximately 500 cSt, the liquid mass flow errors are easily within the limit, mostly falling within $\pm 1.0 \%$. Overall, $70 \%$ of the test points have liquid mass flow errors within $\pm 1.0 \%$.

In Figure 4, 52 out of 53 gas mass flow errors fall within the $\pm 5.0 \%$ error limit recommended by the GOST R 8.615 standard. The only error exceeding the limit, at $-5.7 \%$, occur at the lowest (non-zero) GVF, where achieving a small percentage error in the gas flow rate is more difficult. At the highest viscosity, approximately $500 \mathrm{cSt}$, the gas mass flow errors are well within the limit, mostly falling within $\pm 1.5 \%$. Overall, $80 \%$ of the test points have gas mass flow errors within $\pm 2.0 \%$.

These results suggest that multiphase Coriolis mass flow metering is well suited to heavier oils, with good measurement performance achieved even at GVFs as high as $90 \%$. The results also demonstrate the viability of using viscosity as a parameter for predicting mass flow and density errors. One reason for the improved performance at high GVF in this case may be that the high liquid viscosity leads to slower dynamics - certainly the period of slugging was longer than that observed with a light oil observed in [3]. This holds out the possibility that, with a faster measurement update or other means, it may be possible to extend the GVF range of the NOG technology for light oils.

Finally, it may be worth commenting on the improved results presented here compared with those reported over a decade ago using essentially the same commercial Coriolis flowtube 
and transmitter [9]. There are a number of material differences between the two systems: for example the $75 \mathrm{~mm}$ flowtube used in [9] has a 'parallel' flow path while the 50mm flowtube used here has a 'serial' flow path; these generate different mass flow and density error surfaces. The use of a skid incorporating a flow straightener further assists to regularise the flow profile of the two-phase mixture entering the flowtube. More generally, we would suggest that there has been a gradual improvement in the 'craft' employed by the research team as our experience has grown, for example with regard to the details of our experimental procedures and model-building techniques, which has led to an improved quality in the resulting multiphase solutions.

\section{Acknowledgement}

The work described in this paper was supported by funding from Foxboro/Invensys/Schneider. 


\section{References}

[1] Wang, T, and Baker, R. "Coriolis flowmeters: a review of developments over the past 20 years, and an assessment of the state of the art and likely future directions", Flow Measurement and Instrumentation 40 (2014), pp99-123. DOI:

http://dx.doi.org/10.1016/j.flowmeasinst.2014.08.015

[2] Liu, RP, Fuent, MJ, Henry, MP \& Duta, MD. “A neural network to correct mass flow errors caused by two-phase flow in a digital Coriolis mass flowmeter", Flow Measurement \& Instrumentation, 12, pp53-63, 2001. DOI: https://doi.org/10.1016/S0955-5986(00)00045-5

[3] Henry, MP, Tombs, MS, Zamora, ME, Zhou, FB. "Coriolis mass flow metering for threephase flow: a case study", Flow Measurement and Instrumentation, 30 (2013), pp 112-122. DOI: http://dx.doi.org/10.1016/j.flowmeasinst.2013.01.003

[4] GOST R 8.615, Amended 2008. State system for ensuring uniformity of measurements. Measurement of quantity of oil and petroleum gas extracted from subsoil. General metrological and technical requirements. Federal Agency for technical regulation and metrology. 2008. (in Russian)

[5] Henry, MP, Tombs, MS, Zhou, FB. "Field experience of well testing using multiphase Coriolis metering”, Flow Measurement and Instrumentation, 52 (2016), pp 121-136. DOI: http://dx.doi.org/10.1016/j.flowmeasinst.2016.09.014

[6] Kutin, J, Bobovnik, G, Hemp J, Bajsic, I. "Velocity profile effects in Coriolis mass flowmeters: Recent findings and open questions", Flow Measurement and Instrumentation 17 (2006) pp 349-358. DOI:10.1016/j.flowmeasinst.2006.07.005

[7] Basse, NT. "A review of the theory of Coriolis flow meter measurement errors due to entrained particles", Flow Measurement and Instrumentation 37 (2014), pp107-118. DOI: http://dx.doi.org/10.1016/j.flowmeasinst.2014.03.009 
[8] Millar, G, Belshaw, B. “An investigation into the Performance of Coriolis and Ultrasonic Meters at Liquid Viscosities up to 300 cSt". $26^{\text {th }}$ International North Sea Flow Measurement Workshop, October 2008.

[9] Henry, MP, Tombs, MS, Duta, MD, Zhou, FB, Mercado, R, Kenyery, F, Chen, J, Morles, M, Garcia, C. "Two-phase flow metering of viscous oil using a Coriolis mass flow meter: a case study", Flow Measurement and Instrumentation 17, pp399-413, 2006. DOI: http://dx.doi.org/10.1016/j.flowmeasinst.2006.07.008

[10] Zamora, ME, Henry, MP. “Digital Control of a Coriolis Mass Flow Meter”, IEEE Transactions on Industrial Electronics, Vol. 55, No. 7, July 2008. DOI:

10.1109/TIE.2008.925646 


\begin{tabular}{|r|r|r|}
\hline $\begin{array}{c}\text { Viscosity } \\
\text { (cSt) }\end{array}$ & $\begin{array}{c}\text { Liq flow } \\
\text { (kg/s) }\end{array}$ & \multicolumn{1}{|c|}{$\begin{array}{c}\text { GVF } \\
\text { (\%) }\end{array}$} \\
\hline 45 & 6.00 & $0,10,20$ \\
100 & 0.60 & 90 \\
100 & 3.20 & $10,30,50$ \\
180 & 0.80 & $40,60,70,80$ \\
250 & 3.80 & $10,20,30$ \\
510 & 2.00 & $20,40,60$ \\
\hline
\end{tabular}

Table 1: Experimental parameters used for formal trials 

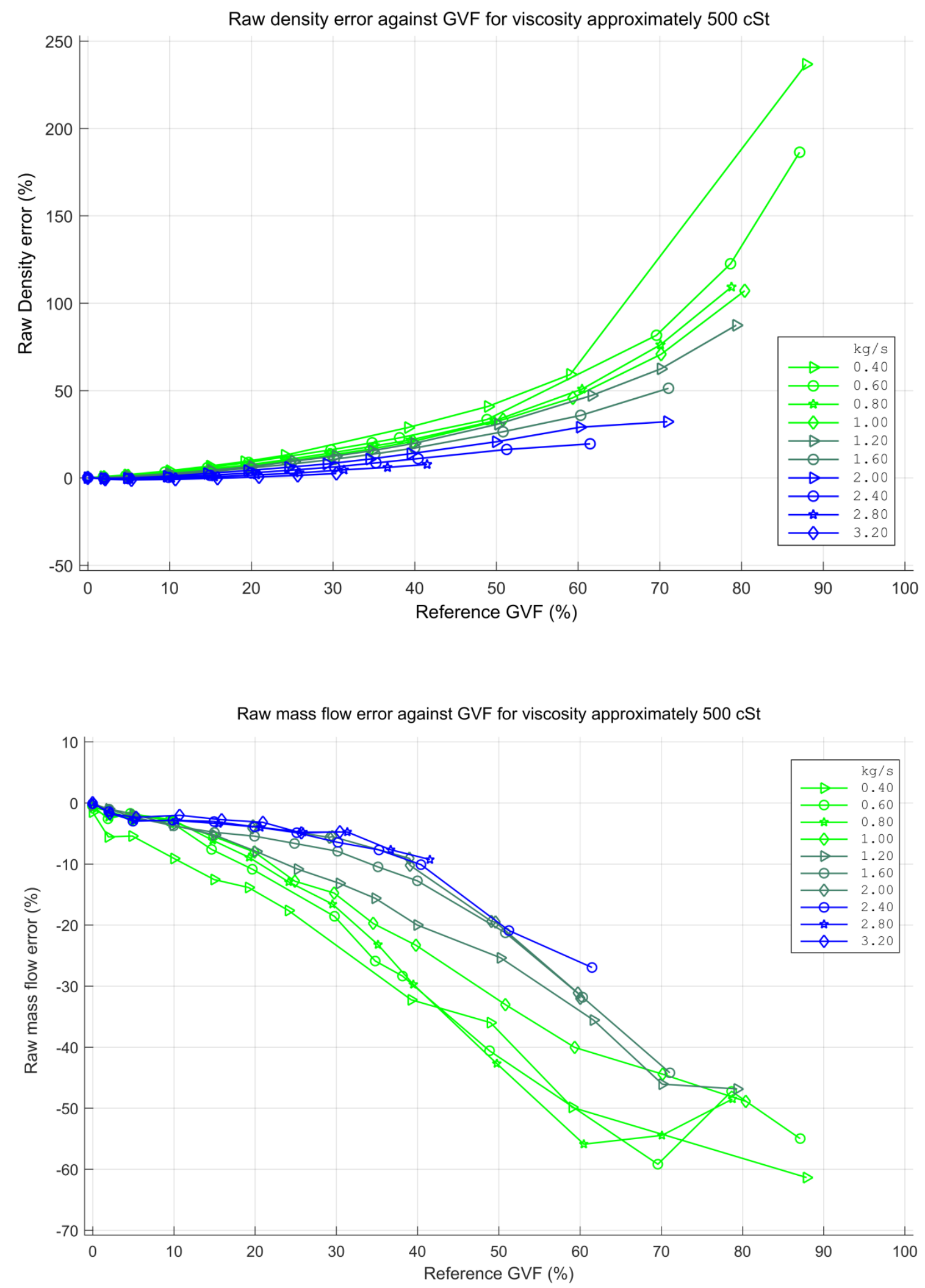

Figure 1. Raw density and mass flow errors for $50 \mathrm{~mm}$ Net Oil and Gas system, with viscosity $500 \mathrm{cSt}$ 



Figure 2. Experimental grid of formal trials of $50 \mathrm{~mm}$ Net Oil and Gas system 

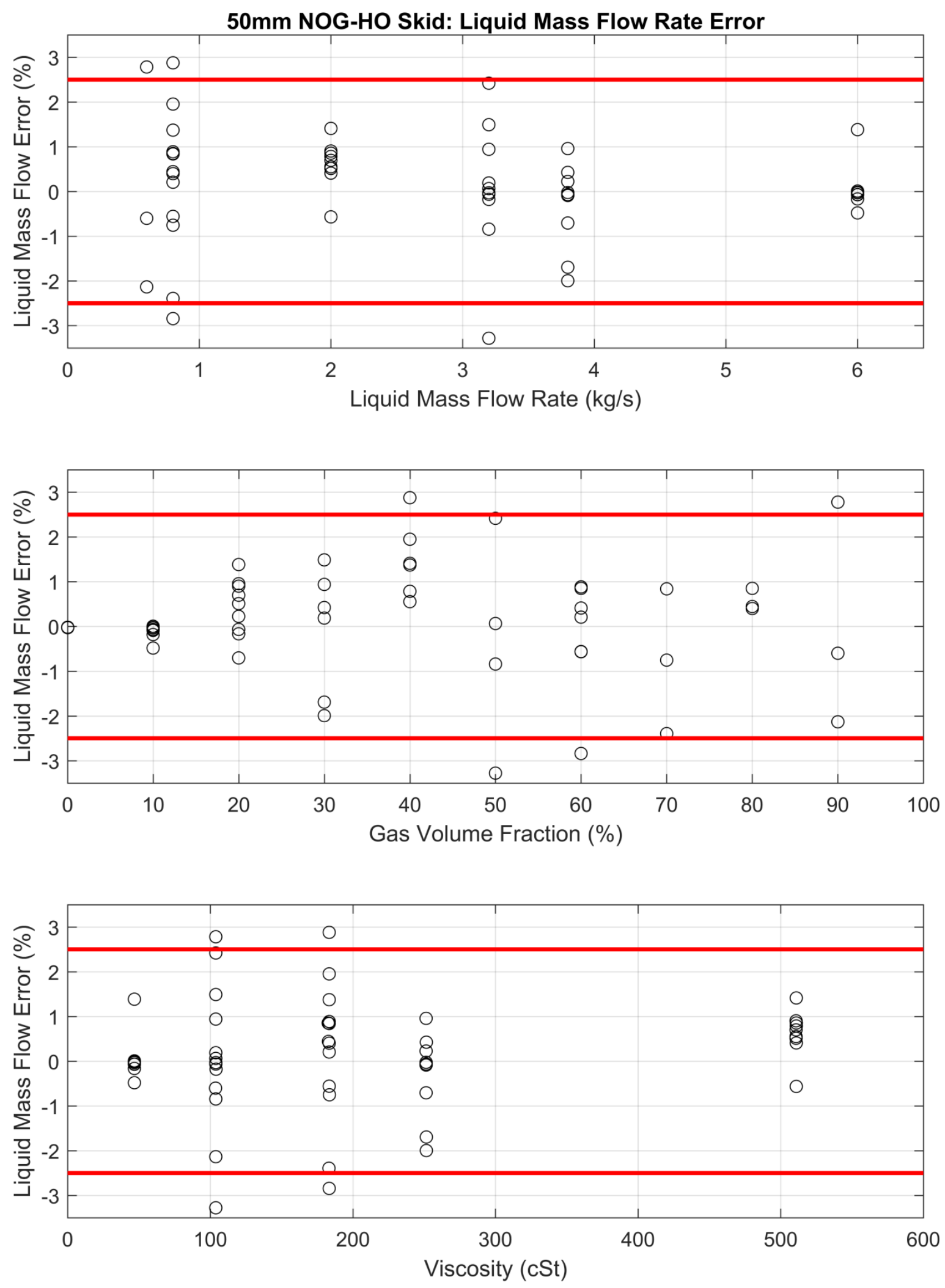

Figure 3. Results for liquid mass flow error in a formal trial of a 50mm Net Oil and Gas system. The red lines show the $\pm 2.5 \%$ error limit recommended by the GOST R 8.615 standard. 

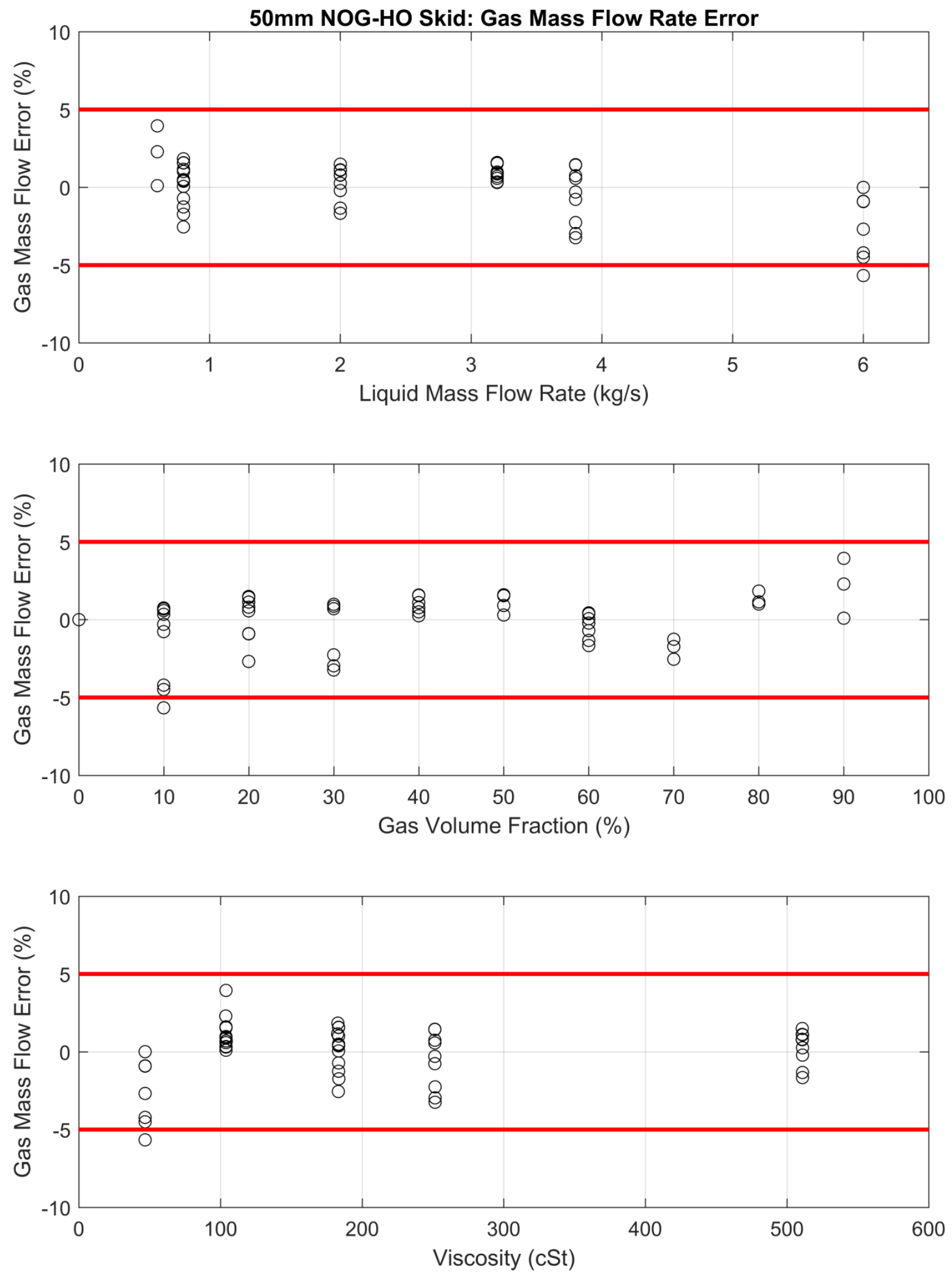

Figure 4. Results for gas mass flow error in a formal trial of a 50mm Net Oil and Gas system. The red lines show the $\pm 5.0 \%$ error limit recommended by the GOST R 8.615 standard. 